\title{
Três fórmulas para compreender "O suicídio" de Durkheim
}

Three formulas for understanding Durkheims "Suicide"

Ricardo Rodrigues Teixeira ${ }^{1}$

As formas elementares de uma concepção religiosa

Le croyant s'incline devant Dieu, parce que c'est de Dieu qu'il croit tenir l'être, et particulièrement son être mental, son âme. Nous avons des raisons d'éprouver ce sentiment pour la collectivité

Emile Durkheim

O positivismo, como se sabe, ao lado de ser uma doutrina científica, é fundado como uma doutrina religiosa por Auguste Comte (1798-1857), logo após a morte de sua amada Clotilde de Vaux (1846), que foi "canonizada" e se constituiu objeto personalizado de culto desta nova religião. Seu marco literário foi a publicação do système de philosophie positive, ou traité de sociologie instituant la religion de l'humanité (1848) e, enquanto uma religião de caráter missionário, não abdicou nem mesmo de ter seu catecismo (Catéchisme

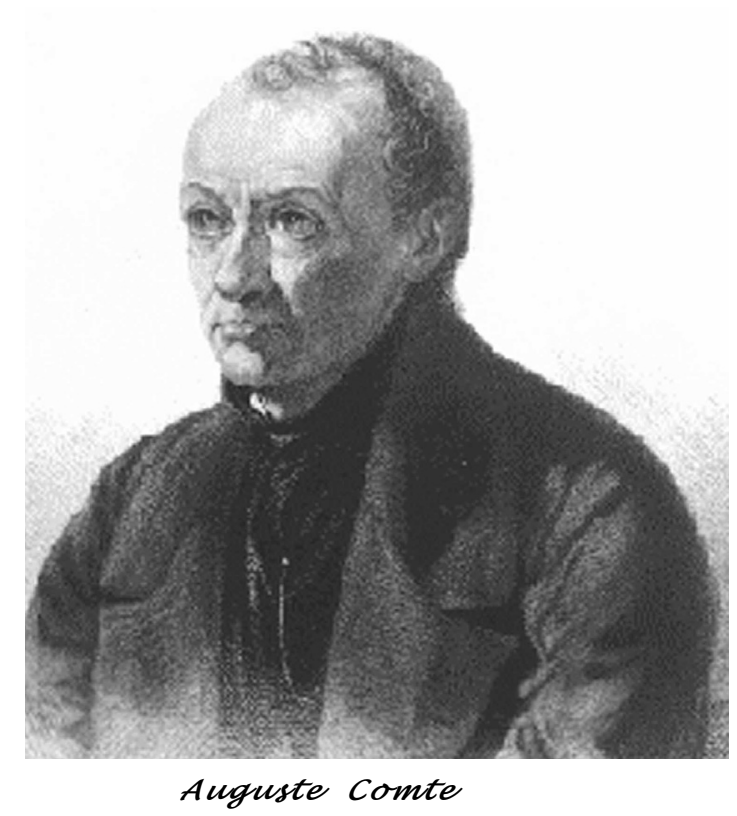
positiviste, 1852).

\footnotetext{
${ }^{1}$ Sanitarista, doutorando em Medicina Preventiva na Faculdade de Medicina de Universidade de São Paulo, FMUSP. <ricarte@uol.com.br>
} 
A religião positivista é fundamentalmente uma sociolatria. Seu Deus, seu objeto de culto último e principal, é a sociedade. Seus crentes concebem a sociedade como uma totalidade orgânica passível de ser conhecida, nos moldes de uma ciência positiva, por uma "física social", cuja "estática" estaria incumbida de produzir uma teoria positiva da ordem. Complementarmente, concebem a história dessa sociedade como a realização de formas definidas como estágios necessários de um progresso, cuja teorização, sempre nos moldes de uma ciência positiva, estaria a cargo de uma "física social dinâmica". A rigor, essa teoria positiva do progresso nada mais é do que a tradução "cientificista" de determinadas convicções (cuja expressão máxima talvez seja o pensamento das Luzes) a respeito do sentido da história européia, que entendem que o sistema medieval, caracterizado pelo poder espiritual (teológico e papal) e pelo poder temporal (militar e feudal), teria sido substituído por um sistema positivo (científico $e$ industrial). Além disso, Comte também interpretava que, à sua época, o curso deste progresso estaria sendo obstaculizado por forças retrógradas, que impediam a Revolução francesa de se completar e tentavam restaurar a Idade Média. O positivismo, como única "autêntica doutrina orgânica", viria restabelecer a ordem e o progresso, sendo, sem dúvida, essa manifesta pretensão, o que sempre conferiu a esta fé "cientificista" um indisfarçável caráter salvacionista.

Este é o esquema básico ou a fé fundante: as formas elementares de uma concepção religiosa a respeito da sociedade. É tão impossível ignorá-la, quanto não perceber as marcas dessa sociolatria comtiana claramente presentes em um de seus mais eminentes discípulos: Durkheim.

Para Durkheim, a sociedade é uma realidade distinta das instituições e dos indivíduos, que não podem existir sem ela. Toda sua sociologia está fundada nas premissas de que é a forma das coletividades que determina as atitudes individuais e de que existe uma autêntica consciência coletiva.

Sabemos que Durkheim provém de uma família de rabinos e que se interessou pelo estudo das religiões, produzindo um clássico da antropologia sobre o assunto, mas, até onde sei, jamais se envolveu com a "religião" de seu mestre (indireto, é bom lembrar), nem freqüentou os "templos positivistas" em que se rendia culto a Clotilde. Seu credo não

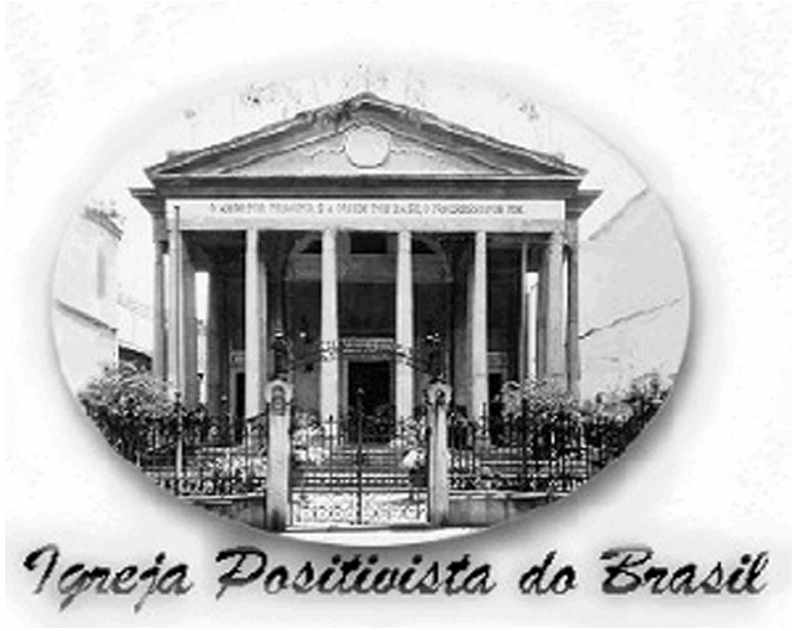
ia além de uma sociolatria mitigada na teoria, mas suficiente para gerar um campo de transcendência para sua sociologia. E é exatamente essa última questão que desejo destacar neste momento: a de que sua sociologia já nasce marcada pela transcendência (esse a priori sobre a ordem e o sentido do progresso social). E, pelo que se vê, uma transcendência fundamentalmente religiosa ou, pelo menos, fundada numa certa mística do social. 


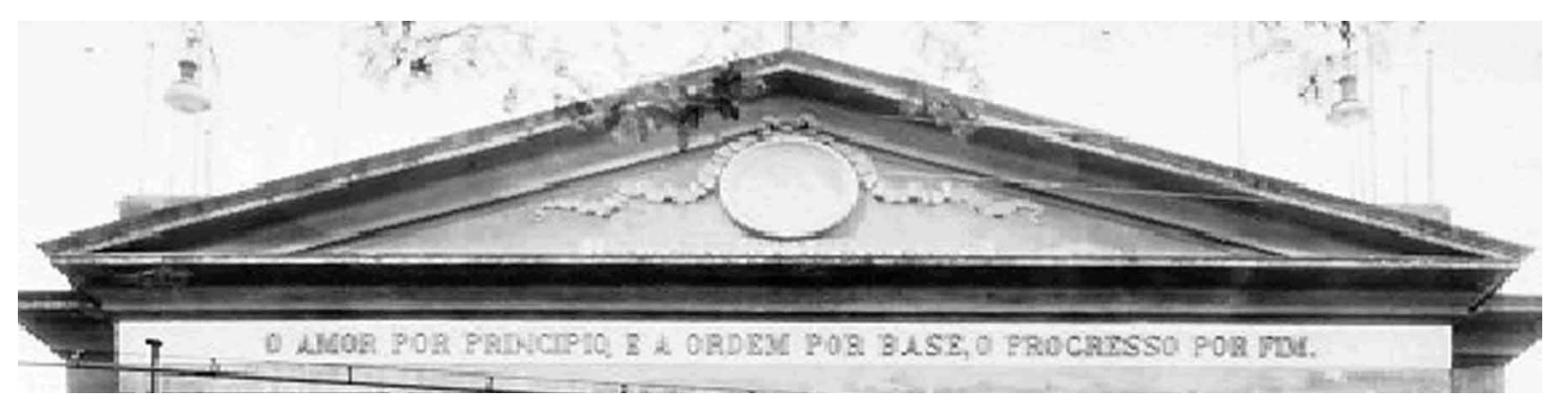

Ora, essa religião positivista pode muito bem ser vista, com vantagens para sua compreensão, como uma espécie de seita particular de uma "religião" ainda mais "católica" (no sentido de mais "universal", mas também no sentido figurado de mais "exata, perfeita") que, com uma certa liberdade, poderíamos chamar de "religião moderna". Ela igualmente possui suas crenças "esclarecidas" a respeito do sentido da história européia e estas também estão fundadas na idéia de que teria havido uma ruptura radical com um passado antigo e medieval. É exatamente essa, aliás, segundo afirma Bruno Latour (1994), a principal crença dos modernos: a de que uma ruptura revolucionária nos separa ("nós", os modernos) dos prémodernos ("eles"). Ainda segundo este sociólogo francês, essa dicotomia básica se desdobraria numa série de outras dicotomias decisivas na caracterização das posições modernas, destacadamente: a dicotomia geral "nós"/ "eles", como nossa forma geral de trato com as diferenças (culturais, sociais, políticas etc.); e a dicotomia entre as "representações dos humanos" nas ciências sociais e as "representações dos não-humanos" nas ciências naturais. "Nós", os sujeitos-civilizados, "eles", os objetos-selvagens: o conjunto humano se encontra tão separado do mundo natural, quanto a civilização moderna nos separa das formas sociais pré-modernas. Contudo, para Latour, essa crença na ruptura revolucionária, a crença moderna, não passa disso mesmo: uma crença. Faz parte do culto antropocêntrico e narcísico da sociedade moderna. Na realidade, tais revoluções jamais se deram! Jamais fomos modernos! (Latour, 1994). Portanto, não estamos cortados com nosso passado, nem somos diferentes d' "eles", nem estamos separados dos nossos "objetos", nem há distinção tão marcada entre as "representações humanas" e as "representações dos objetos", já que cada vez mais nos percebemos - humanos e objetos - misturados em toda parte (de resto, exatamente como "eles" sempre se perceberam...), e isso não sem relação com o fato de os modernos possuírem uma capacidade especialmente marcante de produzir estes seres híbridos.

A interessante proposição latouriana é retomada, no presente contexto, não apenas pela originalidade de sua concepção antropológica da modernidade, que nos oferece saídas interessantes para o impasse estabelecido - como corolário da dicotomia "humano" e "não humano" entre o construtivismo e o realismo, mas sobretudo por nos fazer ver como esses dois grandes pólos de nossa gnose dual estão relacionados com a cisão básica em que está fundada a fé moderna: a crença numa ruptura revolucionária.

No meu esforço de compreender Durkheim, procurei, antes de mais nada, 
situá-lo por referência às linhas e demarcações gerais traçadas por tais crenças positivistas e modernas. Ainda que esse não seja, em si mesmo, o objetivo desse ensaio de interpretação, parece-me um esforço útil para se começar a compreender as regras do modo de conhecer desta sociologia ou, pelo menos, ...

Algumas regras de seu método sociológico

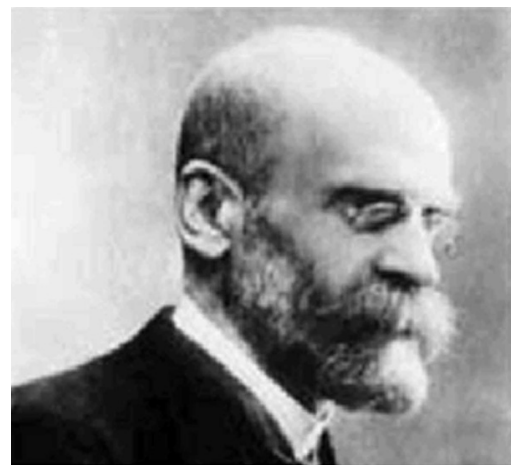

"On n'explique qu'en comparant."

Emile Durkheim

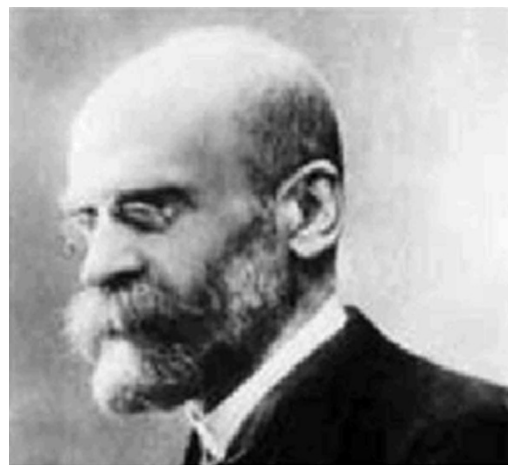

Durkheim é considerado o fundador da Sociologia mas, pelo que foi dito até aqui, sua paternidade deveria mesmo recair sobre Comte, que foi quem primeiro intuiu seu "objeto sui generis". É, contudo, Durkheim que é tido como o legítimo pai, por ter sido ele quem efetivamente estendeu o método das ciências positivas ao estudo dos fenômenos sociais, por ter postulado que o verdadeiro conhecimento sociológico é o conhecimento daquilo que hoje nomeamos as "correlações funcionais entre diversas variáveis".

Assim mesmo, é interessante notar como a démarche durkheimiana, para além deste seu aspecto mais formal, não deixa de dar prosseguimento à elaboração do "objeto sui generis", divinizado por Comte. A extensão do método empregado nas ciências naturais ao estudo dos fenômenos sociais não significou nenhuma espécie de "naturalização" desses fenômenos. Sobre isso, não me parece haver dúvidas: para Durkheim, considerar os fatos sociais como coisas e estudá-los segundo os métodos das ciências positivas, não significava que se tratassem de fenômenos naturais, como queriam, por exemplo, os sociólogos da escola italiana de Pareto (1848-1923), que pretendiam explicar o suicídio a partir das variações de temperatura ${ }^{2}$. Pelo contrário, Durkheim afirma o caráter sui generis do social na própria aplicação do método das ciências positivas, que consiste em observar, comparar e explicar uma variável por outra: Durkheim só admite observar, comparar e explicar um fato social por um outro fato social (as taxas de suicídio só podem ser explicadas em função dos meios sociais, dos divórcios, das crises econômicas etc.). O social só se explica pelo social: proposição teórico-metodológica que não deixa de reverberar a máxima tautológica do positivismo de que o que dá estabilidade à ordem social é a própria... ordem social.

Esse testemunho de fé positivista, ao mesmo tempo em que afirma a natureza singular da coisa social ${ }^{3}$, consagra a separação cortada entre

\author{
${ }^{2} \mathrm{O}$ que foi \\ veementemente \\ refutado por Durkheim, \\ na parte II do capítulo \\ III do Livro Primeiro \\ (Le suicide, 1986; \\ particularmente \\ páginas 94 e seguintes), \\ quando discute os \\ trabalhos de Lombroso \\ e Ferri comparando as \\ taxas de suicídio no \\ Norte e no Sul da Itália.
}

${ }^{3}$ Em suas Regras do Método Sociológico (1895), Durkheim postula que "a primeira regra fundamental (da sociologia) é considerar os fatos sociais como coisas", reafirmando a singularidade que marca esta "coisa" ao definir o "fato social" como "qualquer modo de ação que seja capaz de exercer um constrangimento externo sobre os indivíduos". 
4 "Ao insistir na afirmação de que a ordem social não se baseia em quaisquer

'leis da natureza', não estamos ipso facto tomando posição quanto a uma concepção metafísica de 'lei natural'. Nosso enunciado limita-se aos fatos da natureza empiricamente acessíveis." (p.76-7)

5 "Foi Durkheim quem insistiu mais fortemente sobre o caráter sui generis da ordem social, especialmente em suas Regras do Método Sociológico. $A$ necessidade antropológica da exteriorização foi desenvolvida tanto por Hegel quanto por

Marx."(p.76-7)

\footnotetext{
6 "As tautologias, embora possam nos guiar na nossa busca empírica do conhecimento, não contêm em si qualquer informação sobre qualquer questão factual." (Ayer, 1991, p.69).
}

ciências sociais e ciências naturais, deixando todo o "naturalismo" para estas últimas. Uma vez mais, destaco a já mencionada cisão "moderna", na solução durkheimiana: a afirmação do caráter sui generis do objeto da sociologia tem como preço o divórcio completo entre ação humana $e$ natureza.

É da obra de Peter Berger \& Thomas Luckmann (1974), que extraio uma eloqüente expressão dessa dimensão do pensamento durkheimiano. Como autênticos e qualificados representantes da importante reação antiempirista que marcou a trajetória da sociologia anglo-saxônica (particularmente, norte-americana), na segunda metade do século $X X$, reconhecem o papel da linguagem e da interpretação no fazer das ciências sociais, ou seja, o caráter construído do conhecimento, sendo que o antinaturalismo de Durkheim foi decisivo para que se conduzissem nesta direção:

A ordem social não faz parte da 'natureza das coisas' e não pode ser derivada das 'leis da natureza' ${ }^{4}$. A ordem social existe unicamente como produto da atividade humana. (...) Tanto em sua gênese (ordem social resultante da atividade humana passada) quanto em sua existência em qualquer instante do tempo (a ordem social só existe na medida em que a atividade humana continua a produzi-la), ela é um produto humano. Embora os produtos sociais da exteriorização humana tenham um caráter sui generis, por oposição ao seu contexto orgânico e ambiental, é importante acentuar que a exteriorização enquanto tal é uma necessidade antropológica ${ }^{5}$. O ser humano é impossível em uma esfera fechada de interioridade quiescente. O ser humano tem de estar continuamente se exteriorizando na atividade. Esta necessidade antropológica funda-se no equipamento biológico do homem. A inerente instabilidade do organismo humano obriga o homem a fornecer a si mesmo um ambiente estável para sua conduta. O próprio homem tem de especializar e dirigir seus impulsos. Estes fatos biológicos servem de premissas necessárias para a produção da ordem social. Em outras palavras, embora nenhuma ordem social existente pode ser derivada de dados biológicos, a necessidade da ordem social enquanto tal provém do equipamento biológico do homem. (Berger \& Luckmann, 1974, p.76-7)

O esquema básico ou a fé fundante: o natural apresenta-se no início e depois se retira deixando lugar apenas ao puro fato construído; na produção da ordem social, o fato natural só esteve presente no início e, assim mesmo, como falta, incompletude, como causa da necessidade de uma ordem social, e depois se retirou deixando lugar a uma pura ordem social como causa de si própria, a ordem social remetendo a si própria, sem passar por nenhuma outra referência ${ }^{6} . .$.

Mais uma vez, o que vemos é a dicotomia aprofundar-se na cisão. Além disso, ao se lançar um olhar mais "semiológico" sobre esse modo durkheimiano de conceber o "objeto sui generis" das ciências sociais e seu 
comportamento, é possível compreender um aspecto central em suas "regras" de conhecimento sociológico: seu "objeto" é, em última instância, um "objeto representado"; o fato social é um fato construído com material sígnico. Isso fica evidente, logo nas primeiras páginas da obra em questão, no próprio processo de formulação de uma definição válida de suicídio para os propósitos de seu estudo. Na realidade, o problema se apresenta logo na primeira linha: trata-se do problema do "sentido da palavra suicídio". A pré-condição para que um fato social possa ser estudado cientificamente é que o sentido dos signos que o representa possa ser controlado $e$ estabilizado pelo pesquisador, o que implica uma série de operações lógicogramaticais de construção de enunciados. Só, então, um fato social pode ser cientificamente comparado a outro fato social, ou seja, outro conjunto de signos cujo sentido foi igualmente controlado; do mesmo modo que, paralelamente, no campo das ciências naturais, um objeto natural é comparado a outro, como se não passasse por nenhuma mediação sígnica ou técnica, segundo as crenças realistas próprias às visões positivistas e modernas das ciências naturais.

O esquema básico ou a fé fundante: o social e o natural são duas "naturezas" separadas e incomunicáveis, seus objetos não são da mesma ordem de realidade e não são intercambiáveis, só podendo produzir explicações dentro de sua própria ordem; a unificação das duas "naturezas" só se realiza sob a forma única do método científico que se aplica aos dois tipos de objetos que as constituem: observar a ocorrência dos fatos, compará-los a outras ocorrências da mesma ordem para, a partir destas comparações, procurar explicá-los.

À Sociologia, só cabe estudar os fatos produzidos pelos atos humanos. Como é o caso dos suicídios.

Da divisão do suicídio social

\author{
Chaque société est prédisposé à fournir um contingent déterminé de \\ morts volontaires. Cette prédisposition peut donc être l'objet d'une \\ étude spéciale et qui ressortit à la sociologie. \\ Emile Durkheim
}

Todas as questões expostas nas partes precedentes são parâmetros importantes na leitura e compreensão do estudo de Durkheim sobre o suicídio enquanto fenômeno social.

Em primeiro lugar, temos a já mencionada construção lógico-gramatical da categoria suicídio. Ela segue rigorosamente os dois eixos fundamentais da linguagem: o paradigmático e o sintagmático. Constrói a definição útil de suicídio efetuando a composição sintagmática que percorra todas as equivalências paradigmáticas essenciais para esta definição, equivalências paradigmáticas que marcam as escolhas que incluem ou excluem os eventos que cabem na definição. Esquematicamente, temos mais ou menos os seguintes passos:

1 morte resultante de um ato perpetrado pela própria vítima;

2 morte resultante de um ato, positivo ou negativo, perpetrado pela 
própria vítima;

3 morte resultante, direta ou indiretamente, de um ato, positivo ou negativo, perpetrado pela própria vítima;

4 morte resultante, direta ou indiretamente, de um ato, positivo ou negativo, perpetrado pela própria vítima, que sabia que esse resultado se produziria (o que, então, pressupõe a noção de "tentativa de suicídio", sempre que esse ato for incapaz de fazer com que a morte suceda).

Nous disons donc définitivement: On appelle suicide tout cas de mort qui résulte directement ou indirectement d'um acte positif ou négatif, accompli par la victime elle-même et qu'elle savait devoir produire ce résultat. (Durkheim, 1986, p.5)

Mas, o fato assim definido ainda não está suficientemente elaborado para ser tema de trabalho do sociólogo. $\mathrm{O}$ ato individual de um suicida pode ser assunto para a psicologia; para a sociologia, temos que fazer a passagem do fato singular para o conjunto dos suicídios cometidos numa sociedade. E, só assim, estará concluída a construção de seu "objeto sui generis":

Com efeito, se em lugar de apenas vermos os suicídios como acontecimentos particulares, isolados uns dos outros e que demandam ser examinados cada um separadamente, nós considerássemos o conjunto dos suicídios cometidos numa sociedade dada, durante uma unidade de tempo dada, constata-se que o total assim obtido não é uma simples soma de unidades independentes, um todo de coleção, mas que ele constitui por si só um fato novo e sui generis, que possui sua unidade e sua individualidade, conseqüentemente sua natureza própria, e que, ademais, é uma natureza eminentemente social. (Durkheim, 1986, p.8)

Bem, uma vez obtida a definição lingüística da coisa a ser estudada, passa-se à aplicação do método das ciências positivas: em primeiro lugar, observar a ocorrência, principalmente as variações de ocorrência no tempo e no espaço, da coisa estudada (no caso, a "taxa de mortalidade-suicídio própria à sociedade considerada"); em seguida, comparar as ocorrências (as "taxas") encontradas em diferentes momentos (anos) da mesma sociedade e em diferentes sociedades; $e$, por fim, com base nestas comparações, procurar uma explicação social da coisa (no caso, explicar as causas sociais do suicídio).

De um ponto de vista semiótico-lingüístico, o método positivo repete a operação lógico-gramatical sobre os dois eixos básicos da linguagem: a busca do sintagma explicativo resultante das comparações entre as múltiplas variáveis paradigmáticas. Esta operação comparativa é da máxima importância nas ciências sociais, porque é por ela que se resgata plenamente a dimensão "referencial" do conhecimento sociológico e se mantêm vivas as aspirações realistas próprias a uma ciência positiva: é nela que se evidencia a realidade do "referente" das construções intelectuais sociológicas. Ainda em 
termos semióticos (e de uma semiótica pierceana, relida por Roman Jakobson, 1995), temos que as aproximações comparativas produzem signos copulativos, verdadeiros "ícones de relação" (diagramas, como são chamados por Charles Sanders Pierce) que reativam a função de similitude (a "iconicidade") do signo com seu objeto de referência, já que as comparações entre grandezas (taxas, variações comparadas das taxas, média das taxas, desvio máximo e mínimo da média das taxas, tabelas e outras representações diagramáticas) são representações de proporções reais, representações das únicas características do objeto diretamente observadas no real e que atestam, por assim dizer, sua identidade sui generis.

Antes de mais nada, Durkheim (1986) compara a taxa de mortalidadesuicídio com a taxa de mortalidade geral, particularmente suas variações ao longo do tempo e observa que: "Não somente a taxa (de mortalidadesuicídio) permanece constante durante longos períodos de tempo, mas sua invariabilidade é mesmo muito maior do que aquela observada nos principais fenômenos demográficos" (p.11), já suspeitando que isso se tratasse de um indício do forte lastro social das taxas de suicídio observadas numa sociedade.

Em seguida, compara as variações anuais nas taxas de suicídio (que só acusam discretas mudanças), com as variações entre diferentes sociedades (que podem ir do dobro ao quádruplo ou ainda mais), o que lhe permite concluir que as taxas de suicídio são, portanto, "num grau bem mais alto que as taxas de mortalidade, pessoais a cada grupo social do qual elas podem ser vistas como um índice característico" (Durkheim, 1986, p.13).

Em suma, temos sempre o mesmo esquema geral operando em dois eixos (o da permanência das taxas ao longo do tempo para uma mesma sociedade $e$ o da variação das taxas quando comparamos diferentes sociedades) $e$ confirmando o sentido social daquelas taxas:

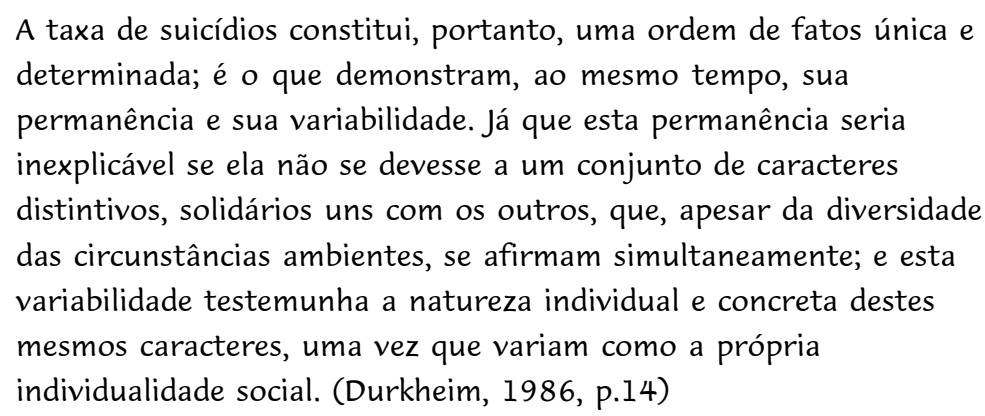

Minha presente leitura, reconhecidamente circunscrita a alguns aspectos bastante restritos e formais do multifacetado estudo de Durkheim, e que sequer chega a comentar seus resultados, quer ser acima de tudo uma contribuição para a decifração do modus operandi do pensamento deste autor, do seu modo de conhecimento. Sobretudo isso: o encontro com uma "forma de pensar", ou seja, encontro em que me detenho concentradamente nas "formas do pensamento", descobrindo seus fundamentos "religiosos", suas cumplicidades com uma certa sociolatria: sua fé fundante, seu esquema básico. 
No recém lançado romance-documentário da escritora inglesa Susan George, $\mathrm{O}$ relatório Lugano, os métodos de eliminação de Auschwitz são comparados aos métodos (tidos como mais eficazes) de autoeliminação dos excluídos (ou

"descartáveis", como denomina o Comandante Marcos das guerrilhas zapatistas) na fase neoliberal do capitalismo.
No entanto, mesmo ficando mais circunscrito ao modo de conhecer do que ao efetivamente conhecido, não poderia deixar de fazer ao menos um comentário no campo dos resultados e, com ele, encerro este ensaio de interpretação.

No plano teórico, Durkheim propõe a categorização de quatro tipos de suicídios (egoísta-altruísta, anômico-fatalista), baseado no grau de desequilíbrio de duas forças sociais: integração social e regulação moral. Dedica uma parte importante do Livro II (Das causas e tipos sociais) ao suicídio egoísta, cujas altas taxas estariam relacionadas aos fenômenos ligados a uma diminuição da integração social (por exemplo: maiores taxas entre homens solteiros do que entre casados). Particularmente interessante, no capítulo II, a discussão a respeito de suicídio e religião, de fato uma discussão a respeito da relação entre suicídio e "individualismo religioso", por meio da comparação entre as taxas de suicídios de católicos e protestantes (nesse ponto, cumpre enfatizar que as comparações de Durkheim entre as taxas de suicídio de católicos e protestantes e suas especulações sobre o "individualismo" não contradizem as interpretações de Weber (1864-1920), relacionando a "ética protestante" e o "espírito do capitalismo". Esta relação entre suicídio e baixa integração social me parece um dos resultados mais interessantes de sua investigação. Nos termos de sua teoria da integração social, enunciada em $A$ Divisão do Trabalho Social (1893), temos que as forças sociais que contribuem para a anomia e o egoísmo são o resultado natural do declínio da "solidariedade mecânica", sem a adequada instituição da "solidariedade orgânica", que decorreria da divisão do trabalho e da industrialização.

Ora, a "solidariedade orgânica", cada vez mais, só parece se tratar de um artigo de fé do ideário religioso positivista, enquanto a sociedade científicoindustrial moderna (o sistema positivo) se revela mesmo uma grande produtora de "egoísmo" e "des-integração social", com suas conseqüentes elevadas taxas de suicídio. Mais do que isso, o que a sociedade científicoindustrial tem efetivamente nos revelado, em sua fase atual, é a face mais sinistra da tanatocracia, sendo geradora de índices crescentemente altos de mortes voluntárias, ou seja, mortes em que os próprios indivíduos "deliberam" sua auto-eliminação, para o cumprimento das taxas sociais de morte ${ }^{7}$.

Esse, talvez, o irônico Suicídio de Durkheim: o suicídio da sua idéia de progresso...

Emile Durkheim (1858-1917)

1893 - Division du travail social

1895 - Règles de la méthode sociologique

1897 - Le suicide

1912 - Les formes élémentaires de la vie religieuse

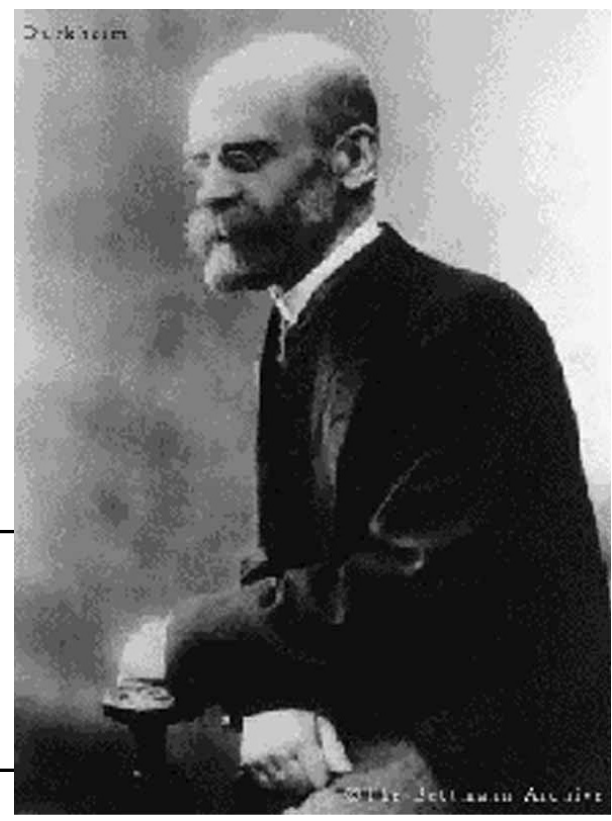


ESPAÇO ABERTO

\section{Referências}

AYER, A. J. Linguagem, verdade e lógica. Lisboa: Presença, 1991.

BERGER, P., LUCKMANN, T. A construção social da realidade - tratado de Sociologia do Conhecimento. Petrópolis: Vozes, 1974.

DURKHEIM, E. Le suicide. Paris: PUF, 1986.

GEORGE, S. O relatório Lugano. São Paulo: Boitempo, 2002.

JAKOBSON, R. Lingüística e Comunicação. 20.ed. São Paulo: Cultrix, 1995.

LATOUR, B. Jamais fomos modernos. Rio de Janeiro: Editora 34, 1994.

This is an essay interpreting the sociology of Durkheim, based on a brief contextualization of his thoughts within the scope of a given view of modernity and of a particular approach to his "Suicide". Divided into three parts, the text intends to explore certain aspects of this Sociology, while at the same time exposing one of its possible aporiae.

KEY WORDS: Sociology; suicide; religion and science.

Trata-se de um ensaio de interpretação da sociologia durkheimiana, a partir de uma breve contextualização de seu pensamento no quadro de uma certa visão da modernidade e de uma particular leitura de sua obra "O Suicídio". Dividido em três partes, o texto procura explorar alguns sentidos desta Sociologia, ao mesmo tempo que expõe uma de suas possíveis aporias.

PALAVRAS-CHAVE: Sociologia; suicídio; religião e Ciência.

Tres fórmulas para comprender "El suicidio" de Durkheim

Se trata de un ensayo de interpretación de la sociología durkheimiana, a partir de una breve contextualización de su pensamiento en el cuadro de una cierta visión de la modernidad y de una particular lectura de su obra "El Suicidio". Dividido en tres partes, el texto intenta explorar algunos sentidos de esta Sociología, al mismo tiempo que expone una de sus posibles aporías.

PALABRAS CLAVE: Sociología; suicidio; religión y Ciencia. 